\title{
GESTÃO ESTRATÉGICA DO CONHECIMENTO NO CONTEXTO ORGANIZACIONAL BRASILEIRO: PROPOSTA DE MAPEAMENTO CONCEITUAL
}

\section{STRATEGIC KNOWLEDGE MANAGEMENT IN THE BRAZILIAN ORGANIZATIONAL CONTEXT: CONCEPTUAL MAPPING PROPOSITION}

\author{
Rivadávia C. D. de Alvarenga Neto ${ }^{1}$; Ricardo Rodrigues Barbosa ${ }^{2}$ \\ ${ }^{1}$ FEAD MINAS - Belo Horizonte - Brasil riva@alvarenganeto.com.br \\ ${ }^{2}$ Universidade Federal de Minas Gerais - UFMG - Belo Horizonte - Brasil \\ ricardobarbosa@eci.ufmg.br
}

\begin{abstract}
Resumo
Este artigo apresenta-se como uma tentativa de demarcação conceitual da temática conhecida como gestão do conhecimento (GC). Longe de almejar propor uma solução definitiva ou um modelo acabado, espera-se contribuir para um melhor entendimento da área. Propõe-se um mapeamento conceitual integrativo adaptado daquele originalmente proposto por CHOO (1998), o qual se associa à idéia de contexto capacitante e às várias abordagens e ferramentas gerenciais metaforicamente denominadas de "guarda chuva conceitual da GC". Essas abordagens $e$ ferramentas, interligadas, contribuem para a construção de um marco teórico-conceitual abrangente que se apresenta como um ponto de partida para um melhor entendimento da GC. Para a consecução de tal fim, relatar-se-ão estudos de casos realizados em três organizações atuantes no Brasil. As conclusões sugerem que não se gerencia o conhecimento, apenas se promove ou se estimula o conhecimento através da criação de um contexto organizacional favorável.
\end{abstract}

Palavras-chave: gestão do conhecimento, contexto capacitante, guarda chuva conceitual da gestão do conhecimento.

\section{Indrodução}

A emergência de um paradigma tecno-econômico baseado em inovação, informação e conhecimento, bem como a crescente consolidação de tecnologias como a microeletrônica, a tecnologia de informação e as redes de computadores, trazem à tona questões complexas e multifacetadas para as organizações contemporâneas. De acordo com STEWART (1998), o ano I da era informacional ou do pós-industrialismo é o ano de 1991. A análise do autor tomou como base os dispêndios de capital nos Estados Unidos, assim como registrados pela Agência de Análise Econômica do Departamento de Comércio Norte Americano, no período 1965-1991. Comparou-se 
o dispêndio das empresas americanas com bens de capital típicos da era industrial - motores e turbinas, equipamentos de controle e de distribuição elétrica, máquinas para trabalho em metal, equipamentos para tratamento de materiais e equipamentos industriais em geral, máquinas para serviços, equipamentos para campos de mineração e petrolíferos, máquinas agrícolas e de construção - vis-à-vis ao dispêndio de capital com equipamentos de informação - computadores e equipamentos de telecomunicações.

Vistas no GRÁFICO 1, abaixo, as duas linhas - dispêndios de capital na era industrial e dispêndios de capital na era da informação - se cruzam em 1991. Conclui-se que a partir de 1991 as empresas passam a gastar mais com equipamentos que coletam, processam, analisam e disseminam informações e menos com equipamentos típicos da era industrial, como máquinas e equipamentos para engenharia de produção.

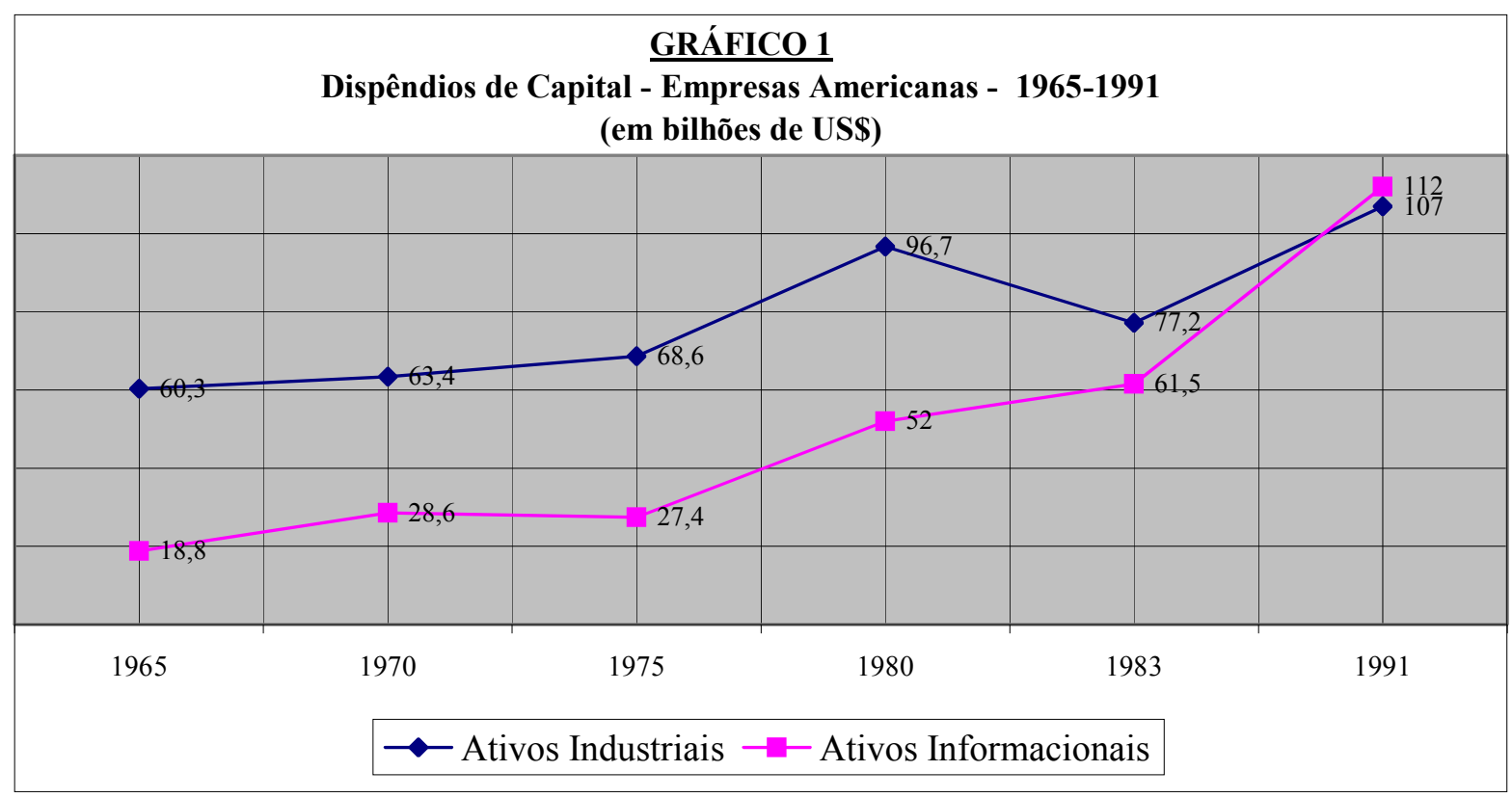

Fonte: adaptado de STEWART, 1998.

Essa transição da "velha rigidez dos átomos para a fluidez dos bits" nas organizações vem suscitando inúmeras discussões a respeito da miríade de novas terminologias criadas na era da informação. As organizações deparam-se, cada vez mais, com novos termos como "gestão do conhecimento", "comunidades de prática", "gestão estratégica do capital intelectual", "aprendizagem organizacional", "gestão estratégica da informação", "inteligência competitiva" e outros mais. Essas diferentes perspectivas refletem diferentes concepções do que são o conhecimento e a própria organização. Para ALVARENGA NETO (2002) e MARCHAND \& DAVENPORT (2004), grande parte do que se faz passar por gestão do conhecimento (GC) é na verdade gestão da informação, mas a GC vai além da gestão da informação, visto que incorpora outras preocupações como, por exemplo, a criação e o uso do conhecimento nas organizações. 
A gestão da informação é apenas um dos elementos da GC e ponto de partida para quaisquer outras iniciativas e abordagens associadas à GC.

Muitos pesquisadores arriscaram definições para a GC. WILSON (2002) examinou as bases de dados da "Web of Science" - em período compreendido entre 1981 até 2002 - e constatou a grande diversidade de conceitos atribuídos à GC, re-afirmando toda a polêmica e controvérsia terminológica. Esse autor constatou o crescimento vertiginoso e exponencial das publicações com a expressão "gestão do conhecimento", conforme mostra a FIGURA 1:

Figura 1 - Publicações com a expressão ‘Gestão do Conhecimento' - Web of Science

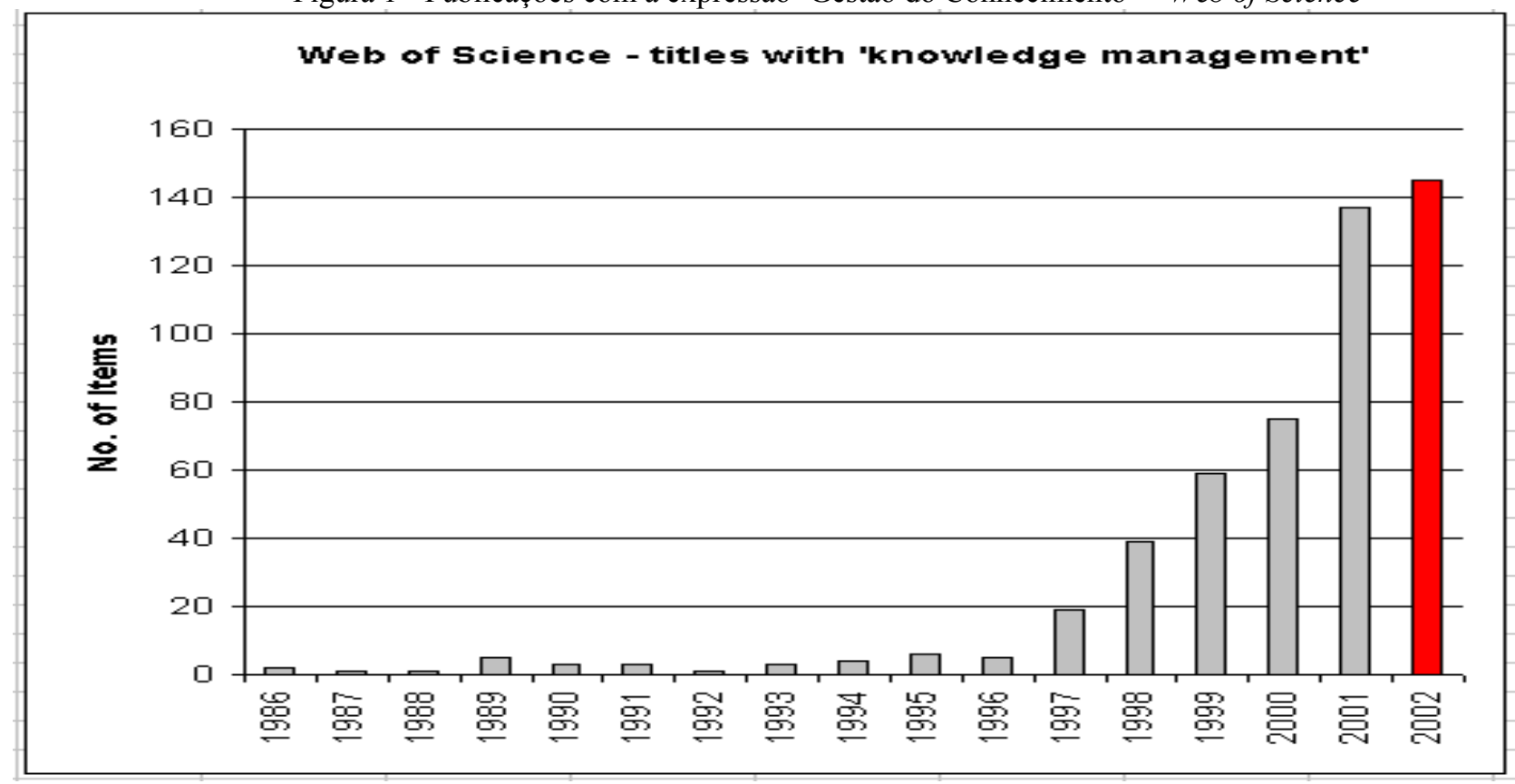

Fonte: WILSON, 2002.

$\mathrm{O}$ atual debate a respeito da GC revela-se também, e principalmente, em recente publicação de autores das áreas de biblioteconomia e ciência da informação, como DAVENPORT \& CRONIN (2000). Esses autores sugerem que, embora muita atenção acadêmica e profissional tenha sido devotada à GC na última década, o conceito aparenta ser usado de maneiras diferentes em vários domínios. Além disso, cada domínio clama para si que a compreensão parcial da temática represente a articulação definitiva do conceito Trata-se de uma deriva semântica ou de uma mudança conceitual? (DAVENPORT \& CRONIN, 2000). Esses autores propuseram-se a explorar o conceito de gestão do conhecimento no contexto de três domínios interessados na área, que são a biblioteconomia e ciência da informação, a engenharia de processos e a teoria organizacional.

O objetivo da proposta de DAVENPORT \& CRONIN (2000), intitulada "tríade da gestão conhecimento", configura-se na proposição de uma ferramenta ou instrumento de análise que sirva para explorar as tensões que possam surgir em quaisquer organizações comprometidas com a gestão do conhecimento, onde diferentes domínios possuam diferentes compreensões. A "tríade da GC" 
pode ser utilizada para identificar conflitos ou embates territoriais e contribuir para um entendimento coletivo entre os atores do espaço da GC nas organizações.

No primeiro domínio, a GC é predominantemente vista como gestão da informação. No segundo domínio, a GC é vista como a gestão do "know-how" e freqüentemente igualada à tecnologia da informação. No terceiro domínio, a GC denota uma mudança conceitual maior, do conhecimento como recurso para o conhecimento como uma capacidade. Nesta última perspectiva, o que é gerenciado não é um recurso, mas o contexto que tal prontidão é manifestada e tal contexto é visto como um espaço de interação entre os conhecimentos tácitos e explícitos de todos os membros de uma organização. A novidade da proposta de DAVENPORT \& CRONIN (2000) é a contribuição para a compreensão da natureza mutável do complexo ambiente baseado no conhecimento no qual vivemos e trabalhamos.

Debates como esses, que se associam à indefinição conceitual e toda a controvérsia gerada ao redor do termo e do tema "gestão do conhecimento", motivaram a realização de uma pesquisa, a qual ainda se encontra em andamento, a respeito de como as organizações brasileiras entendem, definem, implementam, praticam e avaliam a gestão do conhecimento, quais foram os motivos que as levaram a essa iniciativa e o que elas esperavam alcançar com isto. Partes dos resultados desse estudo serão apresentados neste artigo.

\section{Gestão do conhecimento: Modelos, Mapas e Tentativas Conceituais}

Uma vez estabelecidos alguns fundamentos essenciais e eixos temáticos, apresenta-se a proposta de um mapeamento conceitual integrativo de gestão do conhecimento que pode ser expresso através da convergência de três pilares: a) o modelo proposto por CHOO (1998), b) a idéia do contexto capacitante como sugerida por VON KROGH, ICHIJO \& NONAKA (2001) e c) a metáfora do "guarda-chuva conceitual da GC".

Para CHOO (1998), “organizações do conhecimento” são aquelas que fazem uso estratégico da informação para atuação em três arenas distintas e imbricadas, a saber: a) sensemaking ou a construção de sentido, b) criação de conhecimento, por intermédio da aprendizagem organizacional e c) tomada de decisão, com base no princípio da racionalidade limitada de Herbert Simon.

Sob o aspecto de construção de sentido, CHOO (1998) afirma que o objetivo imediato do sensemaking é permitir aos membros da organização a construção de um entendimento compartilhado do que é a organização e o que ela faz. Reflexões estratégicas devem ser feitas acerca da missão, da visão, dos valores e da cultura organizacional e deve-se também abrir espaço para que as pessoas construam significado para seus trabalhos e suas vidas. Uma declaração de visão ambiciosa e desafiadora revela a intenção organizacional e mostra-se assaz valiosa e contributiva. O objetivo de longo prazo do sensemaking é a garantia de que as organizações se 
adaptem e continuem a prosperar em um ambiente dinâmico através da prospecção do ambiente organizacional em busca de informações relevantes que as permitam compreender mudanças, tendências e cenários acerca de clientes, fornecedores, concorrentes e demais elementos. As organizações enfrentam questões como a redução da incerteza e o gerenciamento da ambigüidade. A inteligência competitiva e do concorrente, a monitoração ambiental, a prospecção tecnológica e atividades correlatas são iniciativas empresariais que têm como um de seus objetivos a construção de sentido a respeito de questões para as quais não existem respostas claras. O QUADRO 1, abaixo, apresenta, de forma esquematizada, e sob uma perspectiva informacional, o processo de construção de sentido em contextos organizacionais.

Quadro 1 - Processo de construção de sentido

\begin{tabular}{|c|c|c|}
\hline Necessidade de Informação & Busca de Informação & Uso da Informação \\
\hline $\begin{array}{l}\text { - Quais são as novas } \\
\text { tendências da } \\
\text { indústria/setor? }\end{array}$ & $\begin{array}{ll}\text { - } & \text { Escaneamento ambiental } \\
\text { - } & \text { Sistema de informações }\end{array}$ & 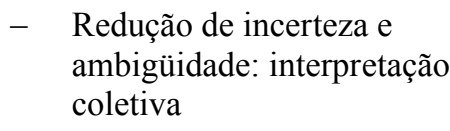 \\
\hline $\begin{array}{l}\text { - Quais são as competências } \\
\text { essenciais dos concorrentes? }\end{array}$ & - Pesquisas & $\begin{array}{l}\text { Construção de } \\
\text { conhecimento }\end{array}$ \\
\hline $\begin{array}{l}\text { - O quê os nossos clientes } \\
\text { valorizam? }\end{array}$ & & $\begin{array}{l}\text { compartilhado. } \\
-\quad \text { Processo decisório } \\
\end{array}$ \\
\hline
\end{tabular}

Fonte - adaptado de CHOO, 1998.

A criação do conhecimento é o processo pelo qual as organizações criam ou adquirem, organizam e processam a informação, com o propósito de gerar novo conhecimento através da aprendizagem organizacional. O novo conhecimento gerado, por sua vez, permite que a organização desenvolva novas habilidades e capacidades, crie novos produtos e serviços, aperfeiçoe os antigos e melhore seus processos organizacionais. O QUADRO 2 fornece uma analogia entre modelos de criação de conhecimento e permite inferências entre suas similitudes e dissonâncias.

\begin{tabular}{|c|c|c|}
\hline $\begin{array}{c}\text { PROCESSOS DE } \\
\text { CONHECIMENTO } \\
\text { (WIKSTRÖM \& NORMANN } \\
\text { 1994) }\end{array}$ & $\begin{array}{c}\text { FASES DE CRIAÇÃO DO } \\
\text { CONHECIMENTO } \\
\text { (NONAKA\& TAKEUCHI 1997) }\end{array}$ & $\begin{array}{l}\text { ATIVIDADES CONSTRUTORAS } \\
\text { DE CONHECIMENTO } \\
\text { (LEONARD-BARTON 1998) }\end{array}$ \\
\hline \multirow{2}{*}{$\begin{array}{l}\text { Processos Generativos: } \\
\text { gerando novo conhecimento }\end{array}$} & \multirow{2}{*}{$\begin{array}{l}\text { Compartilhamento do } \\
\text { conhecimento tácito } \\
\text { Criação de conceitos }\end{array}$} & Solução compartilhada de problemas \\
\hline & & Experimentação e prototipagem \\
\hline \multirow{2}{*}{$\begin{array}{l}\text { Processos Produtivos: } \\
\text { operacionalizando novo } \\
\text { conhecimento }\end{array}$} & Justificação de conceitos & \multirow{2}{*}{$\begin{array}{l}\text { Implementação e integração de novas } \\
\text { metodologias e ferramentas }\end{array}$} \\
\hline & Construção de arquétipo & \\
\hline $\begin{array}{l}\text { Processos Representativos: } \\
\text { difundindo e transferindo novo } \\
\text { conhecimento }\end{array}$ & Conhecimento de níveis cruzados & Importação de conhecimento. \\
\hline
\end{tabular}

Fonte: CHOO , 1998, p.130. 
O terceiro componente do modelo de CHOO (1998) é a que se refere ao processo decisório. Aqui, a empresa deve escolher a melhor opção dentre todas as que se configuram e perseguí-la com base na estratégia empresarial. O processo decisório nas organizações, conforme a visão de MARCH \& SIMON (1975), é constrangido pelo princípio da racionalidade limitada. Várias decorrências podem ser enumeradas da teoria das decisões, CHOO (1998) e MARCH \& SIMON (1975) enumeram algumas delas:

(i) o processo decisório é dirigido pela busca de alternativas que sejam boas o bastante, em detrimento da busca pela melhor alternativa existente;

(ii) a escolha de uma alternativa implica a renúncia das demais alternativas e a criação de uma seqüência de novas alternativas ao longo do tempo - entende-se a relatividade como um custo de oportunidade, que aponta também para a avaliação das alternativas preteridas;

(iii) uma decisão completamente racional iria requerer informações além da capacidade de coleta da empresa e também um processamento de informações além da capacidade de execução de seres humanos.

A criação do conhecimento organizacional é a ampliação do conhecimento criado pelos indivíduos, se satisfeitas as condições contextuais que devem ser propiciadas pela organização. Isso é o que VON KROGH, ICHIJO \& NONAKA (2001) denominam “contexto capacitante”. Sob essa ótica, a compreensão da palavra gestão, quando da sua associação com a palavra conhecimento, não deve ser entendida como sinônimo de controle. Este é um passo extraordinariamente complexo, uma vez que crescemos, trabalhamos e aprendemos em uma sociedade industrial, inserida em um modo de produção capitalista e que impingiu à palavra gestão, no contexto da práxis empresarial, o significado mais nefasto para a palavra controle. Gestão, no contexto capacitante, significa promoção de atividades criadoras de conhecimento em nível organizacional e a GC assume uma nova perspectiva hermenêutica - de gestão do conhecimento para o significado de "gestão para o conhecimento". NONAKA \& TAKEUCHI (1997) e VON KROGH, ICHIJO \& NONAKA (2001) enumeram os vários elementos constituintes do "contexto capacitante", a saber: intenção ou visão do conhecimento organizacional, cultura e comportamento organizacionais, caos criativo, redundância, variedade de requisitos, mobilização dos ativistas do conhecimento, autonomia e delegação de poderes, além de questionamentos acerca da estrutura organizacional, layout e hierarquia, dentre outros. 
Finalmente, a metáfora do "guarda-chuva conceitual da GC" pressupõe que debaixo do mesmo são abarcados vários temas, idéias, abordagens e ferramentas gerenciais, concomitantemente distintos e imbricados. Dentre esses, podem ser destacados a gestão estratégica da informação, gestão do capital intelectual, aprendizagem organizacional, inteligência competitiva e comunidades de prática. É justamente a inter-relação e a permeabilidade entre esses vários temas que possibilitam e delimitam a formação um possível referencial teórico de sustentação, ao qual intitula-se "gestão do conhecimento". Ou seja, defende-se que a GC seja vista como uma área "guarda-chuva". O feedback do modelo se dá pela classificação dos temas inseridos no guardachuva dentro do modelo de CHOO (1998). A inteligência competitiva é uma iniciativa de sensemaking ou construção de sentido, a gestão estratégica da informação e as comunidades de prática se encaixam na temática de criação de conhecimento e assim por diante.

Recorrer-se-á, uma vez mais, a CHOO (2002) para o encerramento desta seção. Esse autor sugere um esquema conceitual passível de ser utilizado para a comparação de possíveis estratégias de gestão da informação e do conhecimento. Como ponto de partida, esse autor sugere o modelo intitulado "Janela de JOHARI", uma abordagem que descreve a dinâmica da comunicação e da interação humanas e tem a gênese de seu nome a partir dos primeiros nomes de seus inventores, Joseph Luft e Harry Ingham. Sua linha de chegada é a proposição da criação de uma janela da gestão do conhecimento, apresentada no QUADRO 3:

Quadro 3 - Janelas da Gestão do Conhecimento

\begin{tabular}{l|ll}
\hline \multicolumn{1}{c|}{ Sabemos o que sabemos } & \multicolumn{1}{c}{ Sabemos o que não sabemos } \\
\hline$-\begin{array}{l}\text { Provisão de acessos às informações e } \\
\text { facilitação do compartilhamento do } \\
\text { conhecimento }\end{array}$ & $-\quad$ Busca de informação direcionada \\
$-\quad \begin{array}{l}\text { Intranets, Portais, Taxonomias, Esquemas } \\
\text { Classificatórios e Benchmarking. }\end{array}$ & $-\quad \begin{array}{l}\text { Promoção de criação do conhecimento } \\
\text { Desenvolvimento, Pesquisa de Mercado. }\end{array}$ \\
\hline $\begin{array}{l}\text { Não sabemos o que sabemos } \\
-\quad \text { Auditoria de Informações }\end{array}$ & $-\quad \begin{array}{l}\text { Monitoração Ambiental } \\
\text { Mapeamento do Conhecimento }\end{array}$ \\
\hline $\begin{array}{l}\text { Comunidades de Prática, Redes de } \\
\text { Conhecimento. }\end{array}$ & $-\quad \begin{array}{l}\text { Descoberta do conhecimento } \\
\text { Planejamento de Cenários, Prospecção no }\end{array}$ \\
\hline
\end{tabular}

Fonte: Adaptado de CHOO, 2002, p.261.

\section{O Método}

Acredita-se que a atividade de pesquisa não deva ser apreendida como empreendimento meramente racional, aquele de que se fala com ênfase e segurança, mas aquele que também tem o efeito de aumentar o temor ou a angústia (BOURDIEU, 1998). Com base nessa assertiva, é mister o 
afastamento da mera discussão terminológica acerca do campo conhecido como gestão do conhecimento (GC) e é condição essencial a exploração de um gradiente conceitual que vem se desenhado no campo, conforme proposta enunciada por ALVARENGA NETO (2002), ALVARENGA NETO \& NEVES (2003), ALVARENGA NETO \& BARBOSA (2003) e ainda SOUZA \& ALVARENGA NETO (2003).

Em suma, trata-se de elaborar um sistema coerente de relações que deve ser posto à prova como tal. É necessário alcançar a compreensão de que o conhecimento é algo que se constrói a partir de outros conhecimentos sobre os quais se exercita a apreensão, a crítica e a dúvida. Deve-se levar em conta ainda que qualquer tentativa de representação do real será sempre mais imperfeita do que ele é e que é absolutamente necessário o processo de socialização entre pesquisadores para permitir o avanço do conhecimento na área, tendo-se em mente que a inovação acontece na fronteira entre mentes criativas em sinergia de propósitos.

Tendo como ponto de partida os fundamentos supracitados, este artigo apresenta-se como uma tentativa de demarcação conceitual da temática conhecida como gestão do conhecimento. Longe de almejar propor uma solução definitiva ou um modelo hermético e acabado, espera-se contribuir para a formulação de um melhor entendimento da área, suas fronteiras e abrangências.

Como forma de se estudar as visões e iniciativas concretas das empresas no campo da gestão do conhecimento, foram realizados estudos de casos em três grandes organizações brasileiras que implementaram programas de GC, a saber: (i) o Centro de Tecnologia Canavieira (CTC), (ii) a Siemens do Brasil e (iii) a "Empresa X" - que não havia autorizado ainda a utilização de seu nome quando da publicação deste trabalho - uma empresa internacional de auditoria e consultoria. $\mathrm{O}$ estudo envolveu a realização de pesquisa documental (documentos em papel e arquivos eletrônicos), entrevistas semi-estruturadas e observação direta.

\section{Análise Preliminar de Resultados}

Observou-se, com base na investigação, que os principais motivadores para a GC nas organizações estudadas giram em torno de constatações acerca dos seguintes aspectos:

(i) inexistência de práticas de compartilhamento e proteção de informações e conhecimentos, levando à re-invenção da roda e à duplicação de esforços,

(ii) problemas com a coleta, tratamento, organização e disseminação de informações, denotando ausência de uma gestão estratégica da informação,

(iii) reconhecimento de que a informação e o conhecimento são os principais fatores de competitividades dos tempos atuais e 
(iv) premência da criação de um contexto capacitante na organização vis-à-vis à necessidade de se endereçar questões culturais e comportamentais.

Abaixo encontram-se depoimentos dos entrevistados, nas empresas estudadas, os quais confirmam tais constatações:

"[...] cada área da empresa tinha métodos idiossincráticos de armazenamento, gestão e explicitação de conhecimentos. [...] a empresa está hoje preocupada com o conhecimento porque ele é hoje o principal fator de competitividade. [...] havia problemas na recuperação da informação." (Coordenador de transferência de tecnologia do CTC)

"[...] trinta anos gerando tecnologia e, ao longo do tempo, com o turnover ou aposentadoria, o conhecimento se perdia. [...] algumas áreas ficavam mutiladas e tinham que começar do zero - eram incapazes de reter o conhecimento e reutilizá-lo em proveito próprio. [...] a perda de conhecimento gerado era crítico: ineficientes na captura, pessoas levavam seus arquivos próprios com elas..." (Diretor Superintendente do CTC)

"[...]conhecimentos e informações importantes se perdiam e não eram compartilhados." (Gerente de auditoria da "Empresa X")

"[...] o maior ativo da 'Empresa $X$ 'é o conhecimento das pessoas, fazer com que o conhecimento de seus profissionais seja compartilhado." (Diretora do departamento de auditoria e de recursos humanos da "Empresa $X$ ")

“[...] uma transformação no modelo de gestão: de um modelo muito mais hierárquico, carimba aqui, carimba ali, que é um modelo lento, para um modelo muito mais orgânico em rede. [...] a idéia de GC é essa, quebrar todos os tipos de barreiras: geográficas, temporais, hierárquicas, lingüísticas, pessoais, dentre outras. " (Gerente de gestão do conhecimento e da informação da Siemens)

"[...] acesso rápido aos conhecimentos da organização é um diferencial competitivo." (Gerente de vendas da Siemens)

Constatou-se a ausência de consenso acerca de uma definição para a GC nas organizações estudadas. Contudo, alguns termos são comuns nas respostas dos entrevistados: processo, informação, conhecimento, inovação, explicitação, registro, compartilhamento, cultura organizacional, acesso e utilização, dentre outros. Eis alguns trechos de depoimentos que confirmam tal assertiva:

“[...] não há consenso sobre o que é ou deva ser GC na organização - é um desafio. [...] há uma delimitação das áreas de atuação: tratar a informação,o conhecimento tácito, facilitar o compartilhamento. [...] GC é um processo, tem fases mas não tem fim. [...] processo que visa facilitar compartilhamento, proteção de ativos intangíveis, dentre os quais o conhecimento." (Gestor do conhecimento do CTC) 
[...] não é muito claro, mas é tudo aquilo que se gerencia para a obtenção do conhecimento, inovação." (Diretor superintendente do CTC)

"[...] processo que contribui para colocar os conhecimentos dos colabores em rede." (Diretor Regional da Siemens)

“[...] não é milagre, não é um 'knowledge unlocker plus'. É muito mais uma mudança da filosofia da gestão estratégica da organização. [...] ferramentas para colaboração e criar canais..." (Gerente de gestão do conhecimento e da informação da Siemens)

“[...] GC é processo, não tem fim. [...] processo para captura de todo o conhecimento que permeia a empresa. [...] disponibilizar, usar e compartilhar para o bem da empresa." (Gerente de documentação e informação da "Empresa X")

“[...] GC é como sustentar um ambiente onde há criação, desenvolvimento, troca e disseminação de conhecimentos estratégicos para a organização -é criar o contexto, é um processo que deveria permear todos os processos de negócios da organização." (Coordenador de GC para América do Sul e Central da "Empresa X")

Em seguida, com o objetivo de verificar a proposta intitulada "guarda-chuva conceitual de GC", solicitou-se aos entrevistados que respondessem quais eram os aspectos, abordagens gerenciais e ferramentas considerados sob a égide da área, programa ou projeto de GC em suas respectivas organizações. Eis a síntese das respostas: (a) monitoração ambiental, inteligência competitiva, pesquisa de mercado; (b) gestão estratégica da informação, gestão eletrônica de documentos, mapeamento de processos, (c) gestão do capital intelectual, competências, pessoas e ativos intangíveis; (d) comunidades de prática - reais e virtuais, (e) aprendizagem organizacional, inclusive e-learning; (f) apoio ao processo decisório e (f) criação do contexto capacitante:

"[...] sim, informações do exterior, produtos da concorrência, tendências de mercado, clippings [...] há também uma coleta informal feita por colaboradores que 'pinçam' algo no mercado e colocam na intranet-até mesmo boatos!" (Gerente de Vendas da Siemens)

"[...] a GC é área estratégica ligada à diretoria, levando informações que subsidiam o processo decisório, é assessoria à diretoria." (Gestor do conhecimento do CTC)

"[...] implementar uma rigorosa taxonomia para todo o conteúdo organizacional.” (Pesquisa documental, CTC, 2005)

Por fim, os entrevistados foram inquiridos acerca da ênfase ou aspectos prioritários da GC em suas organizações. Observou-se que a fase inicial e ponto de partida para quaisquer iniciativas de GC - a gestão estratégica da informação - estava em estágios de quase maturidade, com a 
consciência de que é um processo permanente. As organizações procuravam avançar para aspectos relativos ao compartilhamento, à cultura organizacional e à criação do contexto organizacional favorável ou contexto capacitante, Ressalta-se a existência de várias iniciativas genuinamente brasileiras adotadas por tais organizações nestes sentidos, como o "Momento Cultural" no CTC e o "Happy Hour do Saber" na Siemens. Essa iniciativa é
"[...] é uma prática informal de palestras, aonde são compartilhados conhecimentos essenciais da organização de forma mais "tácita" e espontânea. Trata-se de uma iniciativa local especifica, que se enquadra na política geral. As palestras tem duração de uma hora e são ministradas por colaboradores da empresa. (todos podem ser palestrantes: colaboradores, estagiários e terceiros)” (Pesquisa Documental, Siemens do Brasil, 2005)

\section{Conclusões}

Este artigo objetivou uma tentativa de demarcação conceitual da gestão do conhecimento. Longe de almejar uma solução definitiva ou um modelo acabado, esperou-se contribuir para a formulação de um melhor entendimento da área, suas fronteiras e conexões. Elaborou-se um mapa ou modelo integrativo de GC adaptado daquele originalmente proposto por CHOO (1998), associado à idéia de contexto capacitante e às várias abordagens metaforicamente denominadas de "guarda chuva conceitual da GC" que, interligadas, contribuem para a construção de um modelo conceitual abrangente.

Outro corolário do presente trabalho encarregou-se de traçar um fio condutor anexo à construção do referido modelo, através de uma análise preliminar de resultados de pesquisa de campo em três organizações brasileiras. É fundamental o avanço na pesquisa e conhecimento sobre GC pari passu ao afastamento da estéril dissensão derivada da discussão terminológica. A FIGURA 2 apresenta esta proposta de mapeamento conceitual integrativo.

As conclusões sugerem que não se gerencia conhecimento, apenas se promove ou se estimula o conhecimento através da criação de contextos organizacionais favoráveis. O termo gestão do conhecimento tem significado similar ao termo gestão para as organizações da era industrial ou, em outras palavras, a GC revela-se como um repensar da gestão para as organizações da era do conhecimento. Tal ênfase deriva-se do entendimento de que a informação e o conhecimento constituem-se como os principais fatores de competitividade dos tempos atuais para organizações e nações.

Acrescenta-se ainda que a palavra gestão, quando associada à palavra conhecimento, deve ser apreendida como promoção do conhecimento ou estímulo ao conhecimento e a GC assume o significado de uma gestão de e para o conhecimento. Das análises de práticas organizacionais infere-se também que não se endereçam e nem se solucionam questões culturais, comportamentais e 
atitudinais em relação às premissas da GC (compartilhamento de informações e conhecimentos, idéia de que “informação é poder”, etc.) através de punições, ameaças ou ações localizadas. Só se mudam comportamentos através de profundas reflexões, possivelmente seguidas de mudança, acerca das crenças e valores organizacionais, questões essas aludidas na abordagem de sensemaking e que terão grande impacto nas práticas de recrutamento, seleção e gestão de competências.

Figura 2 - Proposta de Mapeamento Conceitual Integrativa da GC

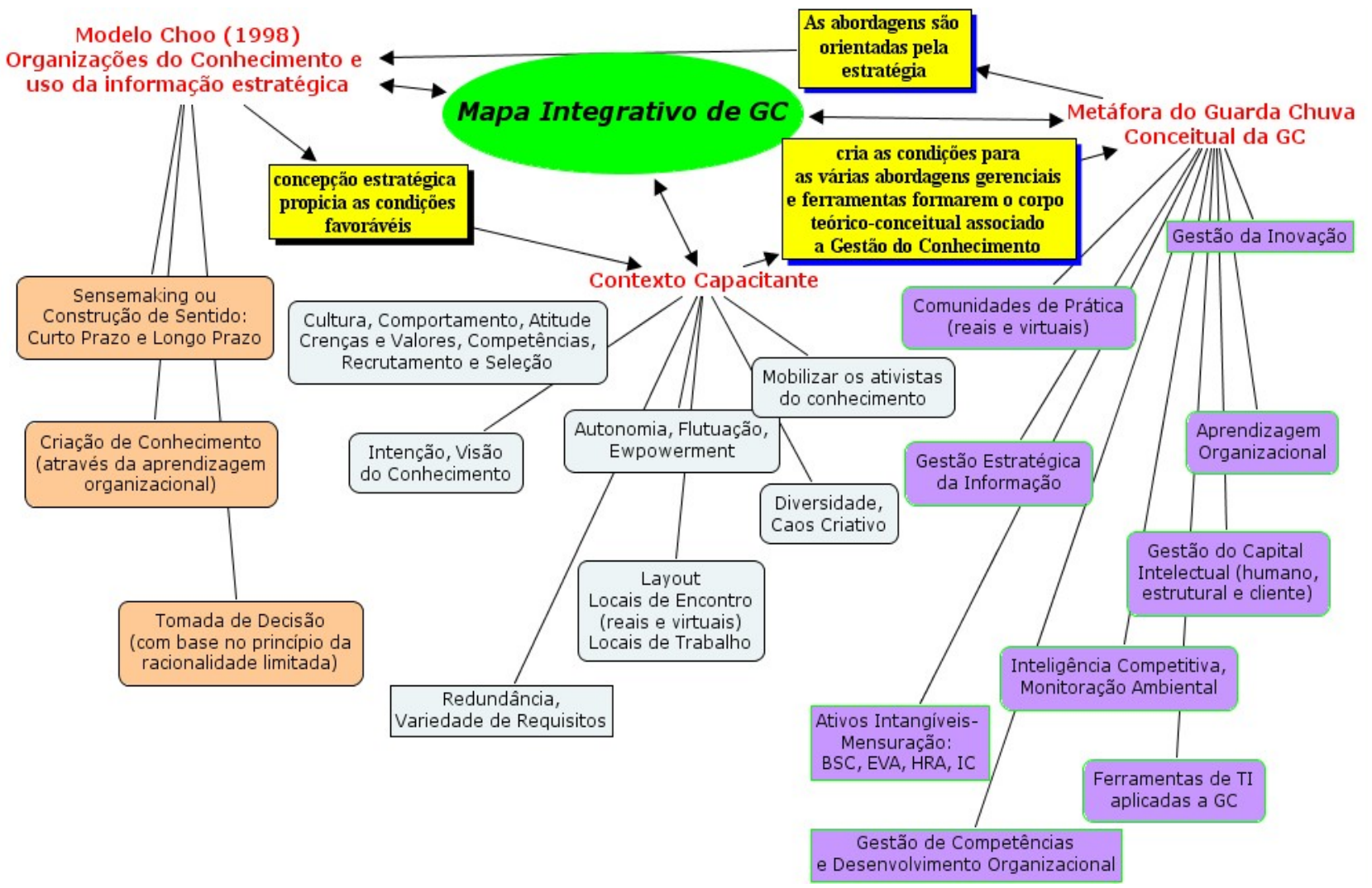

Fonte: desenvolvido pelos autores

Ressalta-se também que a GC é altamente política, requer gestores do conhecimento e é um processo que não tem fim. Concluiu-se também que grande parte do que se intitula ou convenciona chamar de GC é na verdade gestão da informação, contudo a gestão da informação é apenas um dos elementos da GC e ponto de partida para a mesma. Dentre os principais desafios impostos às organizações comprometidas com a GC, destaque para as questões relativas à cultura organizacional, comportamento humano e criação do contexto capacitante, além da premência da criação de um conjunto de indicadores para se medir os retornos e benefícios de GC

\section{Abstract}

This article is an attempt to develop a conceptual demarcation of the theme known as Knowledge Management (KM). Far from proposing a definitive solution or a hermetic model, it hopes to contribute to the formulation of a better understanding of the area/theme as well as its borders and 
scopes. An integrative conceptual map adapted of that originally proposed by CHOO (1998), associated to the idea of the "enabling context" in addition to the several managerial approaches and tools - metaphorically denominated as "conceptual KM umbrella" - is proposed. The proposition of this so called integrative conceptual map aims to contribute to the development of a theoreticalconceptual understanding as a starting point. Case studies of three Brazilian organizations are discussed and analyzed. The conclusions suggest that $\mathrm{KM}$ is an oxymoron, perhaps an impossibility. Knowledge as such cannot be managed, it is just promoted or stimulated through the creation of a favorable organizational context.

Keywords: knowledge management; enabling context; "conceptual knowledge management umbrella".

\section{Referência}

ALVARENGA NETO, R. C. D. Gestão da Informação e do Conhecimento nas Organizações: análise de casos relatados em organizações públicas e privadas. 2002 (Mestrado em Ciência da Informação) - PPGCI, Escola de Ciência da Informação da UFMG, Belo Horizonte.

ALVARENGA NETO, R. C. D.; BARBOSA, R. R. Inteligência competitiva como função da gestão do conhecimento: teoria e prática em perspectiva. KM BRASIL 2003. Encontro da Sociedade Brasileira de Gestão do Conhecimento, São Paulo, Anais do KM Brasil 2003.

ALVARENGA NETO, R. C. D.; NEVES, J. T. R.. Gestão da informação e do conhecimento nas organizações: resultados de análise de casos relatados em organizações públicas e privadas. - Revista de Economia e Administração do IBMEC Educacional, v.2, n.3, p.43-62, jul./set. 2003.

BOURDIEU, P. Introdução a uma sociologia reflexiva. In: Brasil, 1998. p.17-58. . O poder simbólico. 2 ed. Rio de Janeiro: Bertrand

CHOO, C. W. Information management for the intelligent organization: the art of scanning the environment. Medford, New Jersey: Information Today, 2002, $3^{\text {rd }}$ edition.

CHOO, C. W. The Knowing Organization: How Organizations Use Information for Construct Meaning, Create Knowledge and Make Decisions. Nova Iorque: Oxford Press, 1998.

DAVENPORT, E. \& CRONIN, B. Knowledge management: semantic drift or conceptual shift? Journal of Education for Library and Information Science, 41(4): 294-306, 2000.

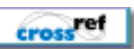

LEONARD-BARTON, D. Nascentes do Saber: criando e sustentando as fontes de inovação. Rio de Janeiro: Editora Fundação Getúlio Vargas, 1998.

MARCH, J. G, SIMON, H. A. Limites cognitivos da racionalidade. In: Teoria das organizações. Rio de Janeiro: Fundação Getúlio Vargas, 1975. p. 192-220 (cap. 6).

MARCHAND, D. A.; DAVENPORT, T. H. Dominando a gestão da informação. Porto Alegre: Bookman, 2004.

NONAKA, I. \& TAKEUCHI, H. Criação de Conhecimento na Empresa: como as empresas japonesas geram a dinâmica da inovação. Rio de Janeiro: Campus, 1997.

SOUZA, R. R.; ALVARENGA NETO, R. C. D. A construção do conceito de gestão do conhecimento: práticas organizacionais, garantias literárias e o fenômeno social. KM BRASIL 2003. Encontro da Sociedade Brasileira de Gestão do Conhecimento, São Paulo, Anais do KM Brasil 2003.

STEWART, T. A. Capital intelectual. Rio de Janeiro: Campus, 1998.

VON KROGH, G., ICHIJO, K., NONAKA, I. In: Facilitando a criação de conhecimento. Rio de Janeiro: Campus, 2001. 
WIKSTRÖM, S.; NORMANN, R. Knowledge and value: a new perspective on corporate transformation. London, UK: Routledge, 1994.

WILSON, T. D. The nonsense of 'knowledge management'. Information Research, v.8, n.1, October 2002.

Dados completos de todos os autores:

Nome completo: Rivadávia Correa Drummond de Alvarenga Neto

Filiação institucional: FEAD Minas - Centro de Gestão Empreendedora

Departamento: Mestrado Profissional em Administração

Função ou cargo ocupado: Professor Titular

Endereço completo para correspondência (bairro, cidade, estado, país e CEP): Rua Ministro Alfredo Valadão 170 - Mangabeiras - Belo Horizonte - Minas Gerais - 30315-080 - Brasil

Telefones para contato: (31) 32230402 - 91048490

e-mail: riva@alvarenganeto.com.br

\section{Nome completo: Ricardo Rodrigues Barbosa}

Filiação institucional: Escola de Ciência da Informação - UFMG

Departamento: Programa de Pós Graduação em Ciência da Informação

Função ou cargo ocupado: Professor Titular

Endereço completo para correspondência (bairro, cidade, estado, país e CEP): Av.Antônio Carlos 6627 - Pampuha - Belo Horizonte, MG - Brasil - CEP: 31270-010

Telefones para contato: (31) 34996120

e-mail: ricardobarbosa@eci.ufmg.br

Recebido para publicação em: 14/06/06

Aceito para publicação em: 01/09/06 